\title{
Da paisagem da imagem à imagem da paisagem e vice-versa
}

Daiane Bertoli*

\section{Resumo}

A paisagem só pode ser apreciada enquanto tal através de um emolduramento que permitiu/permite vê-la como dotada de sentido e valor. Nesta vertente, o artigo analisa o papel das conversões sucessivas da paisagem em imagem e da imagem em paisagem na construção daquilo que é conhecido e percebido como uma evidência. Um evento envolvido pela subjetividade das representações que, transmitido através do tempo, converteu-se no molde do que evocamos como provas objetivas a partir das quais interpretamos e planejamos as paisagens.

Palavras-chave: Paisagem; Imagem; Imaginário; Planejamento.

From the landscape image to the image of the landscape and so vice-verse

\begin{abstract}
The landscape can only be assessed as such by a framing that lead to look at it as endowed of meaning and value. In this regard, the article brings into assessment and analyses the role of successive conversions from the landscape to image and so viceverse, building up what is known and perceived as evidence. An event involved into the subjectivity of the representations that

* Doutoranda do PPGG - CFH/UFSC com bolsa REUNI e financiamento pela CAPES de estágio doutoral no exterior (bertoli.daiane@gmail.com). Obs.: Todos os grifos nos textos citados correspondem a sua versão original. Nas passagens que possuem as fontes escritas em outro idioma a tradução para o português aqui apresentada é de responsabilidade da autora.
\end{abstract}

Geosul, Florianópolis, v. 27, n. 53, p 7-22, jan./jun. 2012 
BERTOLI, Daiane. Da paisagem da imagem à imagem da paisagem ...

passed down over time, became the mold that we evoke as objective evidence from which we do planning and interpret landscape.

Key words: Landscape; Image; Imaginary; Planning.

\section{Introdução}

Se hoje é aceito que a ascensão da sociedade à condição paisagística se deu através da arte ${ }^{1}$, é possível também afirmar que existe uma ligação umbilical entre o espaço concreto e suas representações bem como, uma influência das representações na percepção do espaço concreto. E, não longe disso, sobre como o imaginário passou/passa a se reportar ao existente para projetar sobre ele um porvir desejado. Uma concepção de futuro que adveio a égide instituída de planejamento, mas não sem por em marcha um engenho de objetivação.

Então, a conversão da paisagem em imagem - das representações picturais à fotografia que se disseminam em uma velocidade cada vez maior com o uso da tecnologia e mesmo todas as formas de arte em seu conjunto, em que contribuem para a interpretação/formação/transformação da imagem da paisagem? Quais as ligações que permitem penetrar nessa circularidade que parece perpetuar-se entre a influência do imaginário sobre a paisagem e da paisagem sobre o imaginário e, de novo sua conformação em imagem para que indefinidamente o ciclo prossiga? Como essas interpretações do real impulsionam a

${ }^{1}$ No ocidente suas raízes estão ligadas à pintura flamenca do séc. XV e a invenção e disseminação da perspectiva. (CLAVAL, 2004; BERQUE, 1995). No oriente, a (des)coberta da paisagem, isto é, o ver atrelado a uma capacidade de apreciar, eclodiu com a arte poética por volta de 500d.C. (BERQUE, 2010). Uma abordagem mais específica sobre a gênese das sociedades paisagísticas foge ao escopo deste artigo devido ao seu objetivo e limitação espacial. Ao leitor interessado em um aprofundamento sobre o tema recomenda-se, sobretudo, a leitura de Berque, 1995 e Berque, 2010. 
BERTOLI, Daiane. Da paisagem da imagem à imagem da paisagem ...

moldura de uma paisagem almejada, ou seja, as incorpora enquanto planejamento territorial? E, neste caso, quando a arte se separa da ciência?

A partir desses questionamentos, o presente artigo tece e analisa as imbricações entre paisagem e imagem/imaginário nas interpretações e projeções do real. Assim, objetiva expor as construções que fazem a paisagem ser, ao mesmo tempo, intimamente subjetiva - pois dependente do sujeito que a olha - e parte de um engenho objetivador, pois atua como moldura do que é originado, transmutado e também do que é transmitido, reproduzido, explorado, muitas vezes de maneira naturalizada/internalizada no cerne de uma cultura.

\section{Paisagem: a dança entre imaginário e concreto e o olhar simultaneamente único e coletivo}

A paisagem, isto que parece simplesmente estar aí como algo evidente ao redor de nós, pode, também ela, ser posta como fruto de uma construção humana. Um enquadramento que ao distinguir e conceder valor ao que se vê, soube dar ênfase a outra forma de perceber e se relacionar com o cotidiano, o que no ocidente só passou a existir com a invenção da perspectiva que conferiu hierarquia visual a cena observada, quase mil anos depois dos chineses terem para ela chamado a atenção através de seus versos, como trouxe à apreciação Berque (2010) em seus estudos sobre o oriente.

Da poesia - escrita que fala ao imaginário antes de ser apreciada na, ou como imagem - ao quadro, expressão visual, seguindo para o jardim como um molde da realidade, que se alarga para os esquemas de legitimação da transformação do ecúmeno, ambos apresentam-se como criadores e portadores de signos. Informações estas que em seu senso figurado permitem a leitura como tal somente a quem falam pela incorporação e reconhecimento de um sentido cultural. 
BERTOLI, Daiane. Da paisagem da imagem à imagem da paisagem ...

Num exemplo mais extremo, a rocha contemplada num jardim japonês só pode expor-se para além de uma expressão formal para o ocidental que a aprecia se este tiver sido previamente imbuído de seu significado. Assim, ela se converterá numa representação do mito fundador, em que cada tipo e formato de pedra revela uma ligação íntima com a terra dos imortais e, este saberá também que a posição que ela ocupa no local, se deitada ou em pé, é muito mais que uma disposição aleatória e pode evocar cada um dos elementos que compõe a família a qual o jardim pertence. Porém, não é necessário passar de um extremo a outro do planeta para constatar que as variações de interpretações são múltiplas e dependem do arcabouço de quem as lê para adquirir significado.

Mas, a paisagem não depende apenas do sujeito que olha; um conjunto de coisas efetivamente está lá, e nesse permanecer em si abre-se à apreciação. Porém, esta presença do mundo ao nosso entorno é, como coloca Berque (1995, p.27), depende de uma "união estrutural" entre o ambiente e quem o percebe, pois é só através de um sujeito interpretante que o mundo pode ser provido de sentido. O meio físico, por essa vertente, não se reduz a "um dado que existira em si", ele depende da mobilização de conceitos e impressões para ser enxergado como tal.

Nessa junção com o real em que é revolvida toda complexidade humana de caráter coletivo e individual - e onde o intelecto e a animalidade participam do mesmo jogo - é possível simultaneamente colocar em xeque a existência de uma mesma e idêntica paisagem e tratá-la ainda como irremediavelmente imbricada por um contexto que em muito extrapola o sujeito. É neste sentido que para Berque (1995, p.31-32) a paisagem é simultaneamente "gênese e ampliação": Gênese - na medida em que cada experiência de paisagem é única e não pode ser repetida nem pelo mesmo observador uma segunda vez, pois é ligada a uma percepção que é continuamente resinificadas por outras nuances incorporadas na constância da vida. Ampliação - pois a compreensão da paisagem depende da ativação de memórias 
BERTOLI, Daiane. Da paisagem da imagem à imagem da paisagem ...

diretas (imagens já vistas em fotos, filmes, etc.) e indiretas (aproximações feitas a partir de outras experiências) que são captadas de um sem número de conhecimentos retidos que muitas vezes nisso trabalham em caráter inconsciente.

A representação que se faz de algo, portanto, na medida em que é incorporada e depois movimentada para dar sentido à interpretação, cumpre um papel primordial. Contudo, para que haja representação antes se faz necessário o enquadramento do representado, que, não distante, é limitado por aquilo que se é capaz de perceber, ou, nos dizeres de Nietzsche (2001, p.112), "primeiro tornamos tudo imagem, nossa imagem". Um efeito que precisa ser entendido como um continuum: o emolduramento, por seu turno, é dependente das representações que o embasam, logo, situado historicamente. Seguindo a pista de Nietzsche, o que era primordialmente representação converte-se no modelado daquilo que se tem por certo. A aparência, "verdadeiramente, não é o oposto de alguma essência" (p.95), pois confere à coisa a sua feição, algo que sempre guarda em sua origem alguma desrazão que é tomada como uma verdade pela crença repetida de geração em geração (p.96).

Por essa vertente, a "arte" e a "ciência" - do seu segmento como a física ou mesmo a filosofia - não se distinguem enquanto produtoras e reprodutoras de esquemas de representação e significação. Decompor o movimento originado por uma gota de chuva que cai num lago como uma perturbação mecânica à superfície da água, e que se propaga concentricamente em intervalos regulares passíveis de cálculo, exige, pois, um adestramento da percepção em detrimento a outras formas de representar.

"Nós artistas!" exclamou Nietzsche em 1882 ao intitular o aforismo 59 de Gaia Ciência e a proclamar que as certezas, sobretudo a que se acreditava chegar a conhecer com a metafísica, são também elas parte de um engenho inebriado de sentimentos que pouco se afasta da sensibilidade artística: "Basta amar, odiar, desejar, simplesmente sentir imediatamente o espírito e a força do 
BERTOLI, Daiane. Da paisagem da imagem à imagem da paisagem ...

sonho vêm sobre nós (...)". "Nós, incansáveis e silenciosos andarilhos, em alturas que não vemos como alturas, mas como nossas planícies, nossas certezas!"” (NIETZSCHE, 2001, p. 97). Uma condição que contemporaneamente ecoa pelas diversas áreas do saber como uma contraposição à ideia de separabilidade rígida entre sujeito e objeto, a exemplo da aura retida das palavras de Novarina (2004, p.69) para quem, a existência de modalidades diferentes para compreensão dos fenômenos não as situam nem como contraditórias entre si nem como completamente separadas e sim relacionadas por perseguirem o objetivo comum de "busca de uma verdade". Para o autor, "arte e filosofia aparecem como 'graus' de um mesmo processo de conhecimento, isto é, como modalidades de apreensão do real".

A paisagem, que em sua conceituação primeira refere-se ao olhar, ou ao "ver como", caso preferira-se essa expressão, de modo algum se resume a uma experiência da visão. Se assim o fosse, o observador ao contemplar uma imagem estática ou não - seja ela uma foto, um quadro, uma figura de revista ou de calendário de supermercado, um catálogo turístico, as mensagens em powerpoint que inundam os correios eletrônicos, um filme ou qualquer elemento de divulgação que se tome ligeiramente por fiel à realidade - sentir-se-ia diante de uma experiência plena e o impulso de ir à procura ou não de uma vivência no local visualizado em imagem, ou em um que a ele se assemelhe, restaria em estado latente. A experiência da paisagem envolve todos os sentidos físicos: visão, audição, tato, olfato, paladar. Não é nada inocente a ligação e o apelo que ora se faz à imagem de pratos gastronômicos, mesmo nos folders de divulgação de uma cidade com pouca tradição turística. Essa busca plena de sentidos embebese em outra: a que provoca e é provocada por todo humano sentimento. Observe-se a condição do turista que, satisfeito ao chegar a um ponto considerado de destaque, contempla o mapa, sua insígnia, e o confronta com o real para assegurar-se de estar no bom local. Em seguida, com as representações à sua mão ou em sua mente, lança-se a fotografá-lo, procurando um ponto focal 
BERTOLI, Daiane. Da paisagem da imagem à imagem da paisagem ...

"único" ou aquele que é o mais próximo possível ao que se vê nos cartões postais, ou ainda, põe-se a fotografar-se com o cenário desejado como pano de fundo. Uma procura que é proporcional à consagração dada a algo - nas mais variadas formas - e que tanto pode ser um quadro de um pintor em um museu renomado, quanto um símbolo síntese como a Torre Eiffel em Paris, a Estátua da Liberdade em Nova York, o Coliseu em Roma, ou, em outra escala, a ponte Hercílio Luz em Florianópolis. Uma forma de atrelar sua própria imagem ao que é reconhecido pelo poder simbólico que lhe é atribuído e que, por conseguinte, contribui para reforçar o poder da coisa como símbolo. "Conheço tal coisa, ou tal cidade", "estive lá", são frases comuns, mas que trazem imbuídas o apoderamento inerente ao que se julga "conhecido", ainda que na intimidade sejam a referência ao dispêndio apressado de algumas horas, dias ou semanas no local. Uma condição que à dependência do valor e significado atribuídos por um imaginário social e no seio de uma teia de ralações estabelecidas pode ser convertido efetivamente na capitalização ou potencialização de poder, sobretudo quando o simbólico agrega-se ao que é considerado como erudição.

O papel da representação, aquele que a imagem (em sentido amplo) exerce sobre o imaginário na predileção por "conhecer" tais ou tais lugares, está longe de ser disposto somente como uma função fortuita e massificante. Aquilo que é tido como culto, ligado ao saber, que pode ser o repassado academicamente, desempenha força de atração similar no indivíduo a ele sujeitado pelo contato. É dessa forma que ao historiador apraz conhecer lugares já citados como de distinção histórica, ao geólogo a contemplação in loco de formações geológicas incomuns de cuja existência soube de antemão, ao arquiteto urbanista salta ao sentido a interação com diversos tipos de cidades e experiências urbanas, artísticas e arquitetônicas apreendidas pelas leituras, pelas indicações em aula, ou pela fascinação provocada pelas imagens dos livros de arquitetura. Um conhecimento chancelado que se reafirma e reaviva-se pela adição - e muitas vezes, por uma posterior 
BERTOLI, Daiane. Da paisagem da imagem à imagem da paisagem ...

transmissão - do que foi objeto de experiência direta. Conceito, imagem e realidade se interpenetram e agem um sobre o outro o tempo todo.

A preparação que uma viagem requer para que não se passe desapercebidamente por algo considerado de grande relevância, demonstra também que o grau de importância que se dá a determinados elementos in situ é ao menos em certa medida prédefinido. E, o que é então importante diante deste aparentemente contraditório poder ser enaltecido ou nem notado? Retornemos a um sentido etimológico desta palavra: "importante XVI. Do latim importans - āntis, particípio presente de importāre" 2. "importāre "trazer para dentro"" (CUNHA, 2010). Com esta acepção, nota-se que aquilo que tem importância liga-se ao que o próprio sujeito importa para si, ou seja, uma interiorização de algo que passa por seu crivo como digno de apreço. E aqui, resguardados seus focos e objetivos, não há fundamentalmente uma separação da aplicação do enquadramento, seja no que tange as saídas de campo ligadas à especialidade científica e aquela das visitas turísticas guiadas.

Sob outro ângulo, o idear incessante por experiências paisagísticas característicos da era atual, do qual sua "compulsão fotográfica" é um sinal, como indica Berque (1995, p.45), não passa para o autor, em sua essência antropológica de uma encarnação, um avatar transfigurado da motivação pela "peregrinação às terras encantadas das eras proto-paisagísticas", uma tomada da "imagem pela coisa". Uma apropriação simbólica através de ritos que assumem papel importante no prisma pelo qual a visão do território se constrói.

Embora não se resuma à arte como modalidade restrita, a menos que todo agir humano seja enquadrado como alguma sorte de arte, as condições e os efeitos da criação artística, enquanto produtora e indutora de uma sensibilidade, são a chave que deu

${ }^{2}$ As abreviações foram transcritas com seu sentido original conforme a lista de abreviaturas do referido dicionário para facilitar a sua leitura no contexto deste artigo. 
BERTOLI, Daiane. Da paisagem da imagem à imagem da paisagem ...

condições à sociedade de chegar a seu estágio de percepção atual e tornar-se paisagística. Como enfatiza Berque (1995, p.33-34), foi necessário primeiro a criação de um conjunto de representações que configuraram os elementos que sempre estiveram à disposição da visão dentro de um "esquema estético explicitamente paisagístico" para que a partir daí a paisagem fosse vista e reconhecida como tal. Um patamar que foi ascendido através do trazer a apreciação e fazer ver posto na forma de arte.

Uma capacidade de apreciar, de "conferir valor", que os chineses cantaram em seus versos, ensinando a olhar de outra forma para o ordinário, e que o homem do renascimento soube expressar na construção do ponto de fuga e posicionamento do observador que conferiu ao cotidiano a distância que lhe permitiu apreciar o mundo sob outro aspecto. Novas representações que a partir daí instituíram "a motivação paisagística" em "motivos reconhecíveis por todos" (BERQUE 1995, p. 34) e que nesse ir e vir sucessivos entre imagem e paisagem/paisagem e imagem teve os traços da subjetividade que os criou transformados na força do que parece "obviamente" evidente.

\section{O poder da aparência na construção do "evidente" e do planejamento territorial}

De uma maneira geral, toda prática de paisagem - seja ela perante a resultante de uma ação de planejamento ou frente ao mais inóspito dos lugares - é, em algum grau, um exercício estético. Um arcabouço de conhecimento de todas as ordens é revolvido para dar sentido e valor ao que se vê. Mesmo o arranjo mais tosco dos elementos não se dá de forma completamente aleatória, ainda que o propósito seja mantido no nível não cônscio. Em outras palavras, o evidente não é, ou está evidente: ele pressupõe um esquema de construção.

Uma motivação estética, por sua vez presume a existência de um pré-julgamento, uma noção do que é bom e do que é belo e assim também do que se toma por suas antíteses e toda a gradação 
BERTOLI, Daiane. Da paisagem da imagem à imagem da paisagem ...

ali envolvida. Um rótulo que quando socialmente concedido e reconhecido não passa sem deixar consequências: o "por em valor", do conceito geratriz de paisagem, no âmago de uma sociedade capitalista, converte-se em sinônimo de "quantificação monetária". A "vista" é capaz de alterar o preço de um imóvel e mesmo ser adicionada à fatura de uma estadia de hotel. "Venha morar onde os outros passam as férias" diz o cartaz publicitário de vendas de apartamentos próximos ao mar: em outras palavras, viva com a sensação de ser um turista permanente - não longe do que Berque certa vez retomou como apelido de ideologia do eterno viajante. A especulação imobiliária produz diferenças espaciais; uma série de associações formam-se e reivindicam a "sua paisagem", alegando que tais ou tais construções promoverão a perda de suas características, ou mesmo são eleitas "paisagens" que devem ser, a todo custo, preservadas ou ainda modificadas (o caso das chamadas "limpezas sociais"). Por último, a própria paisagem vira jogo de poder, transforma-se em território, até confundir-se, ela mesma, com um objeto que precisa de formulações mais ou menos precisas para "o bom governo" de seu desenvolvimento futuro. Porém, esses pontos também não explicam o bom e o belo, apenas apropriam-se de algo que parece dado. Afinal, que outra classificação mereceria uma montanha verdejante com seu reflexo espelhado em um lago ou uma praia de águas cristalinas com coqueiros que derramam sua sombra nas areias brancas? Voltemos pois ao centro da questão: o que distingue e conduz à noção do que parece ser evidente.

Não são poucos os exemplos que visam mostrar que o interesse que hoje se projeta na admiração, como menção, das "belezas naturais", dá-se num momento muito recente da história humana (TOURNEUX,1995; BRIFFAUD, 1995; CAUQUELIN, 2000, para mencionar alguns). A "descoberta" do mar, da montanha, do rural - hoje capazes de deslocar multidões à procura de suas "amenidades" - exigiu primeiro a inversão do modo de enxergar o que até então era associado à repulsa. Um padrão que, a citar o Brasil colonial como referência, provocou uma relação da 
BERTOLI, Daiane. Da paisagem da imagem à imagem da paisagem ...

cidade com o mar nas áreas litorâneas distinta da que se tem no presente e, afastado da costa, a que então é chamada de "exuberante floresta" já foi, para o colonizador, a "mata hostil" a ser desbravada.

Nesse caso, como se dá a passagem de uma interpretação à outra para que esta última, ainda que admitidas variações não hegemônicas, torne-se uma visão tão introjetada, a ponto de governar o que passa por "normal", "natural" e fazer a noção de sua construção ser diluída?

Para Cauquelin, (2000, p.81), "É preciso admitir que é uma costura de elementos heterogêneos que governam a sensibilidade de uma época (...). É preciso admitir também a importância da arte nessa fabricação". Uma construção que segundo a autora conduz "a apropriação de uma paisagem que parece, para nós, ser evidente" (op. cit., p.86).

Efetivamente, o apreço que se tem pelas "belezas naturais" não ganha ares concretos na cultura ocidental antes do projeto lançado pelos naturalistas, sobretudo os pintores, que dominaram a representação artística do fim do séc. XIX e que, ao saírem dos ateliês, propõem um olhar admirativo sobre o "real": enfoques da "natureza" (o dia, a noite, as árvores, os rios, as nuvens, etc.) e algumas vezes do rural cotidiano, "fiel" ao que eles "são" (ou "eram" à época). Um olhar que, ao organizar o que se vê, pouco a pouco se espalha a partir de sua estima por uma camada social até que nesse longo trajeto histórico entre conversão do real em imagem e da imagem em realidade, os limites iniciais da tela e os autores são progressivamente esquecidos. Dá-se corpo a uma sensibilidade cultural, que nos dizeres de Chabason (1995, p. 263) "é educada e preparada pela arte". Como reforça o autor, não se vai “(...) procurar na natureza o que nos aprouve na natureza, mas se irá buscar na natureza aquilo que nos seduziu na arte". Em resumo, o que se projeta, para usar a ênfase de Cauquelin (2000, p.18), é uma "admiração por nossa própria maneira de ver" que é alçada da criação de uma coerência intelectual que "empresta ao espetáculo uma evidência". 
BERTOLI, Daiane. Da paisagem da imagem à imagem da paisagem ...

Uma sensibilidade que, em princípio, não corre a uma mesma velocidade para todos, sobretudo em seu olhar estreante. Em outra conotação, o bom e belo são relativos a quem os desvela e os transforma em valores que em primeira mão servem para conferir distinção. Uma arbitrariedade em sua gênese e uma "imposição de valor feita (...) por meio da exposição num local consagrado e consagrante", como ressalta Bourdieu (2007, p. 285). Um entendimento que aqui precisa prudentemente ser alargado para considerar que não é só na arte (sentido restrito) que ao consagrado é conferido o poder de con-sagrar, e por exclusão, o de rechaçar. Um julgamento que também não se desliga de uma esfera moral estabelecida, pois, como argúi Nietzsche (2001, aforismo 114), mesmo a percepção sensível é dependente do "grau de nossa retidão e equidade" que por sua vez é interligado às experiências que tivemos.

O que passa por evidente, porém, não é aquilo de que lembramos mas o fruto do que esquecemos - ou melhor, do que em estado latente armazena-se inconscientemente. É ele que compõe os esquemas mentais através dos quais se classifica de imediato o que se olha, sem dar-se conta de que se trata de uma longínqua história composta por milhares de projeções passadas cujo papel é justamente promover o arranjo e a ordem que nos ajuda a perceber o conjunto das coisas que nos cercam. Uma construção que se dá através do recorte do que nos rodeia e do apagamento de outros possíveis aspectos em função da distinção que provocam no que é mostrado. Uma "orientação imperativa", como classifica Cauquelin (2000)."Não se trata de um olhar inocente, mas de um projeto" (op. cit. p.17).

O que é claro, patente, manifesto para uma sociedade, em determinado ponto histórico, é tanto mais aceito quanto maior a convergência e o encaixe entre suas representações mentais e o que é observado. Uma instituição em que, como distingue Bourdieu (2007, p. 285), quando o olhar que "é produto de um campo", a este campo se dirige, todos os produtos ali inseridos, são imediatamente identificados, nesta afluência entre as coisas e os 
BERTOLI, Daiane. Da paisagem da imagem à imagem da paisagem ...

cérebros, como dotados "de sentido e de valor." Ou, nos dizeres de Heidegger (2010, p.89), a "conformidade com o sendo vale há muito como a essência da verdade". É assim, por exemplo, que se constrói o abismo entre a percepção corriqueira de uma obra de arte e aquela apresentada pelos "iniciados" neste campo que podem elevar seu valor a cifras astronômicas. Uma mesma naturalização do olhar impregnado de valores que cada área tem para com seus objetos.

É, com efeito, que Lacoste (1995) lança um artigo com o objetivo de indagar "A que serve uma paisagem? O que é uma bela paisagem?".

Sua interpretação é menos no sentido de uma fruição e moldura pela arte e direciona-se para outro elemento: a segurança. $\mathrm{O}$ autor procura mostrar a relação entre as estratégias militares e o sentimento do que frequentemente considera-se como uma "bela paisagem". É deste modo que para ele as paisagens que se destacam são as que misturam duas características: a amplitude de visão, ou a visão privilegiada de algo - como a que se tem nos mirantes, topos de montanhas, em alguns edifícios, etc - e a não monotonia. Uma possibilitaria não ser apanhado de surpresa pelos inimigos e poder traçar estratégias de deslocamento e ataque e a outra apareceria como a oportunidade de defesa uma vez que se fica desguarnecido diante do que parece prolongar-se indistinta e indefinidamente e do que se fecha em todas as direções. Em suma, uma combinação entre aberto e fechado que apela à sensibilidade ancestral do corpo.

Um olhar diagonal e concordante se as raízes forem buscadas, já que a arte não deixa de ser também motivada em último estágio pela procura de segurança, estratégia de manutenção da existência diante do medo do vazio, ou da morte, da qual, a imagem é um artifício "(...) necessário para que se assegure a perenidade que dura o prazer, a tensão da vida" como afirma Cauquelin (2000, p.97). Uma via partilhada pelo planejamento como recurso para se chegar ao "bom", à "felicidade", à regência do viver em sociedade como prelúdio de controle da insegurança. 
BERTOLI, Daiane. Da paisagem da imagem à imagem da paisagem ...

Não é por acaso que, como afirma Donadieu (1994, p.68-69), “as utopias revelaram uma busca incessante de paisagem”. Uma lógica que conduziu "a colocar em obra, realmente, as imagens que sugerem a ficção e a estabelecer as paisagens como molduras de uma sociedade desejada".

Por outro lado, a diferença que separa uma criação pontual um jardim ou mesmo um quadro - de seu alastramento transmutado sobre o território ordinário é, conforme Berque (2010, p.172), o poder de evocação que o simbólico carrega sobre o físico, “(...) a capacidade de servir de modelo, visto que os símbolos viajam melhor que as coisas que eles evocam".

Movimento de duas mãos no qual dificilmente se penetra. Entradas sucessivas entre real e feição de real, validade mimética e potencial de evocação da aparência, lembrança e esquecimento, que em conjunto compõem a paisagem, as análises que dela se faz, e o modo como cada sociedade elabora seu arranjo espacial em função da sua interpretação.

\section{Considerações finais}

A sensibilidade de uma época, aquilo que ela toma como suas evidências, seja no âmbito cotidiano ou no acadêmico/científico, guarda infiltrado em si o projeto de uma moldura que em meio a alterações, aglutinações e repasses, pouco a pouco atravessou a espiral temporal para compor o que para nós é, em grande escala, tido como a realidade concreta. Aquilo que nossas traduções e interpretações se empenharam/empenham em tentar mostrar como provas objetivas que, tornadas conhecimento e elevadas a condição de racionalidade, foram postas a serviço da busca de uma pretensa segurança e converteram-se em poder e meio de sustentação na batalha pela vida.

É dessa relação entre lembrança e esquecimento, materialidade e representação, luta entre o desejável e o imprescindível, que a paisagem pode ser o que é: coexistência entre as projeções da nossa consciência e o que simplistamente está 
BERTOLI, Daiane. Da paisagem da imagem à imagem da paisagem ...

aí, mas destituído de propósito sem o nosso olhar. Que em meio a isso, possamos nós, como disse Berque (1995), "guardar a medida humana...".

\section{Referências bibliográficas}

BERQUE, Augustin. Histoire de l'habitat idéal: de l'Orient vers l'Occident. Paris: Éditions du Félin, 2010.

BERQUE, Augustin. Les raisons du paysage: de la Chine antique aux environnements de synthèse. France: Éditions Hazan, 1995.

BOURDIEU, Pierre. O poder simbólico. Rio de Janeiro: Bertrand Brasil, 2007.

BRIFFAUD, Serge. Découverte et répresentation d'un paysage. Les Pyrénées du regard à l'image. (XVIIIe au XIXe siècle) In: ROGER, Alain (org.). La théorie du paysage en France (19741994). France: Éditions Champ Vallon, 1995. p.224-259.

CAUQUELIN, Anne. L'invention du paysage. Paris: Quadrige/PUF, 2000.

CHABASON, Lucien. Pour une politique du paysage (entretien avec Odile Marcel). In: ROGER, Alain (org.). La théorie du paysage en France (1974-1994). France: Éditions Champ Vallon, 1995. p.260-273.

CLAVAL, Paul. A paisagem dos geógrafos. In: CORRÊA, Roberto Lobato; ROSENDAHL, Zeny (orgs). Paisagens, Textos e Identidade. Rio de Janeiro: Eduerj, 2004. p. 13-74.

CUNHA, Antônio Geraldo da. Dicionário Etimológico da Língua Portuguesa. Rio de Janeiro: Lexikon Editorial, 2010. 4a edição revista pela nova ortografia. 
BERTOLI, Daiane. Da paisagem da imagem à imagem da paisagem ...

DONADIEU, Pierre. Pour une conservation inventive des paysages. In: BERQUE, Augustin (org.). Cinque proposition pour une théorie du paysage. France: Editions Champ Vallon, 1994. p.51-80.

HEIDEGGER, Martin. A origem da obra de arte. São Paulo: Edições 70, 2010.

LACOSTE, Yves. A quoi sert le paysage? Qu'est-ce qu'un beau paysage? In: ROGER, Alain (org.). La théorie du paysage en France (1974-1994). France: Éditions Champ Vallon, 1995. p.42-73.

NIETZSCHE, Friedrich. (1882). A Gaia Ciência. São Paulo: Companhia das Letras, 2001.

NOVARINA, Gilles, Les nouvelles modalités de l'analyse urbaine: décrire plutôt que prescrire. In: CHALAS, Yves (coord.). L'imaginaire aménageur em mutation. Paris: L'Harmattan, 2004.

TOURNEUX, François-Pierre. De l'espace vu au tableau, ou les définitions du mot paysage dans les dictionaires française du XVIIe au XXe siècle. In: ROGER, Alain (org.). La théorie du paysage en France (1974-1994). France: Éditions Champ Vallon, 1995. p.194-209.

Recebido em outubro de 2011 Aceito em outubro de 2011 